\title{
Pegadas teromorfóides do Triássico Superior (Formação Santa Maria) do Sul do Brasil
}

\author{
Rafael Costa da Silva ${ }^{1}$, Ismar de Souza Carvalho', Antonio Carlos Sequeira Fernandes ${ }^{2}$ \& \\ Jorge Ferigolo
}

\begin{abstract}
Resumo Pistas de vertebrados do Triássico são abundantes em todo o mundo, mas apenas recentemente foram encontradas na Formação Santa Maria (Triássico Médio a Superior, Sul do Brasil), apesar do rico registro osteológico presente nessa unidade. O material estudado consiste em amostras contendo pegadas e pistas teromorfóides procedentes do afloramento Predebon (porção superior do Membro Alemoa, Formação Santa Maria), situado no Município de São João do Polêsine, Estado do Rio Grande do Sul. Algumas das pegadas encontradas foram atribuídas a Dicynodontipus isp., ao passo que outras foram descritas como Dicynodontipus protherioides isp. nov. Algumas pegadas associadas a estas não puderam ser identificadas, sendo então classificadas como Incertae sedis. As pegadas estudadas não correspondem a subpegadas (undertracks) e foram produzidas em substrato encharcado e muito plástico, tendo ocorrido um breve período de exposição subaérea levando ao endurecimento da superfície antes do seu soterramento. O animal produtor de Dicynodontipus protherioides isp. nov. era quadrúpede, cursorial, com andar alternado e postura semi-ereta, mas tinha pouca flexão lateral da coluna vertebral; os autopódios eram plantígrados a semiplantígrados, sem garras e com almofadas falangeais e plantares. As pistas foram produzidas com andar caminhado e com a cauda tocando o chão. A distância gleno-acetabular do produtor dessas pegadas foi calculada como 2,68 cm. As pegadas estudadas, incluindo Dicynodontipus protherioides isp. nov. e Dicynodontipus isp., podem ser atribuídas a cinodontes de pequeno porte, cujos esqueletos são encontrados nas formações Santa Maria e Caturrita.
\end{abstract}

Palavras-chave: Dicynodontipus protherioides isp. nov., pegadas teromorfóides, cinodontes, Triássico Superior, Bacia do Paraná.

\begin{abstract}
Theromorphoid footprints from late triassic (Santa Maria formation) of southern Brazil. Tracks of triassic vertebrates are abundant all over the world, but they were discovered only recently in Santa Maria Formation (Middle-Late Triassic, Southern Brazil), despite the rich osteological record in this unit. The studied material consists of rock samples containing theromorphoid footprints and tracks from Predebon outcrop (upper portion of Alemoa Member, Santa Maria Formation), located in the municipality of São João do Polêsine, Rio Grande do Sul State. Some of the footprints had been attributed to Dicynodontipus isp., while others had been described as Dicynodontipus protherioides isp. nov. Some footprints associated to these could not have been identified, being classified as Incertae sedis. The studied footprints do not correspond to undertracks and were produced in wet and very plastic substrate. After their production, a brief period of subaerial exposure leads to the hardening of the surface before its burial. The trackmaker of Dicynodontipus protherioides isp. nov. was quadrupedal, cursorial, with alternate pace and half-erect gait, but with little lateral movement of the vertebral column; the autopodia were plantigrade to semiplantigrade, without long claws and with falangeal and sole pads. The tracks were produced in walking gait with the tail touching the ground. The gleno-acetabular distance of the trackmaker was calculated as $2.68 \mathrm{~cm}$. The studied footprints, including Dicynodontipus protherioides isp. nov. and Dicynodontipus isp., can be attributed to small-sized cynodonts, whose skeletons are found in the Santa Maria and Caturrita formations.
\end{abstract}

Keywords: Dicynodontipus protherioides isp. nov, theromorphoid footprints, cynodonts, Late Triassic, Parana Basin.

INTRODUÇÃO Pegadas e pistas de vertebrados do Triássico são relativamente abundantes em todo o mundo, mas apenas recentemente foram encontradas no Brasil. Na Formação Santa Maria (Triássico Médio a Superior, Sul do Brasil) foram registradas pegadas lacertóides, provavelmente produzidas por esfenodon- tídeos, além de registros preliminares de pegadas teromorfóides e dinossauróides (Silva et al. 2005a, 2005b, 2006, 2007a, 2008). A forma de preservação dessas pegadas foi estudada por Silva et al. (2007b). A textura fina da rocha permitiu a preservação de detalhes morfológicos dos icnofósseis, o que os torna valiosos para

1- CCMN, IGEO, Departamento de Geologia, Universidade Federal do Rio de Janeiro, Rio de Janeiro (RJ), Brasil.

E-mail: paleoicno@yahoo.com.br / ismar@geologia.ufrj.br

2- Museu Nacional/UFRJ, Rio de Janeiro (RJ), Brasil. E-mail: fernande@acd.ufrj.br

3- Museu de Ciências Naturais, Fundação Zoobotânica do Rio Grande do Sul, Porto Alegre (RS), Brasil. E-mail: jorge.ferigolo@fzb.rs.gov.br 
a identificação dos organismos produtores e para uma melhor compreensão sobre a gênese das camadas, além de trazer informações sobre morfologia funcional e hábitos de vida dos organismos produtores das pegadas. Outras ocorrências icnofossilíferas da Formação Santa Maria consistem em coprólitos, ao menos um deles com ocorrências de pegadas (e.g. Souto 2001), e um registro de perfurações em ossos feitas por coleópteros (Schwanke \& Kellner 1999, Fernandes et al. 2002).

Neste trabalho identificamos e descrevemos as pegadas teromorfóides da Formação Santa Maria, Triássico Médio a Superior da Bacia do Paraná, Estado do Rio Grande do Sul e tecemos inferências quanto às características morfológicas, biomecânicas e comportamentais dos organismos que as produziram.

MATERIAL E MÉTODOS O material de estudo consiste em dez amostras de rochas contendo icnofósseis de vertebrados e invertebrados, provenientes da Formação Santa Maria, coletadas entre 2002 e 2005 e depositadas na coleção paleontológica do Museu de Ciências Naturais (MCN) da Fundação Zoobotânica do Rio Grande do Sul, situada no Município de Porto Alegre (RS), sob os números MCN.PIC.001, MCN.PIC.002, MCN.PIC.003, MCN.PIC.004, MCN.PIC.007, MCN.
PIC.016, MCN.PIC.017, MCN.PIC.018 a \& b e MCN. PIC.019. As amostras encontram-se referenciadas através da sigla do Museu de Ciências Naturais (MCN), coleção de Paleontologia-Icnologia (PIC), número da amostra e número da pegada. Este material procede do afloramento Predebon (coordenadas $29^{\circ} 38^{\prime} 29,14^{\prime \prime} \mathrm{S}$; $53^{\circ} 26^{\prime} 52,14^{\prime}$ W), situado no Município de São João do Polêsine, Estado do Rio Grande do Sul (Fig. 1).

Expedições foram realizadas entre 2005 e 2006 em parceria com a Companhia de Pesquisa de Recursos Minerais (CPRM, Núcleo de Porto Alegre) a diversos afloramentos das formações Santa Maria e Caturrita na região próxima a São João do Polêsine, RS, objetivando o levantamento de dados geológicos, prospecção e coleta.

Foram confeccionados moldes e réplicas das amostras MCN.PIC.016, MCN.PIC.017 e MCN. PIC.018a \& b segundo técnicas de Rigby \& Clark (1965) com o objetivo de facilitar a identificação, descrição e ilustração dos icnofósseis. As réplicas encontram-se depositadas na coleção paleontológica do Instituto de Geociências, Departamento de Geologia, Universidade Federal do Rio de Janeiro.

Os parâmetros morfométricos das pegadas e pistas foram mensurados com o auxílio do programa Image J (Abramoff et al. 2004). Foram utilizados os

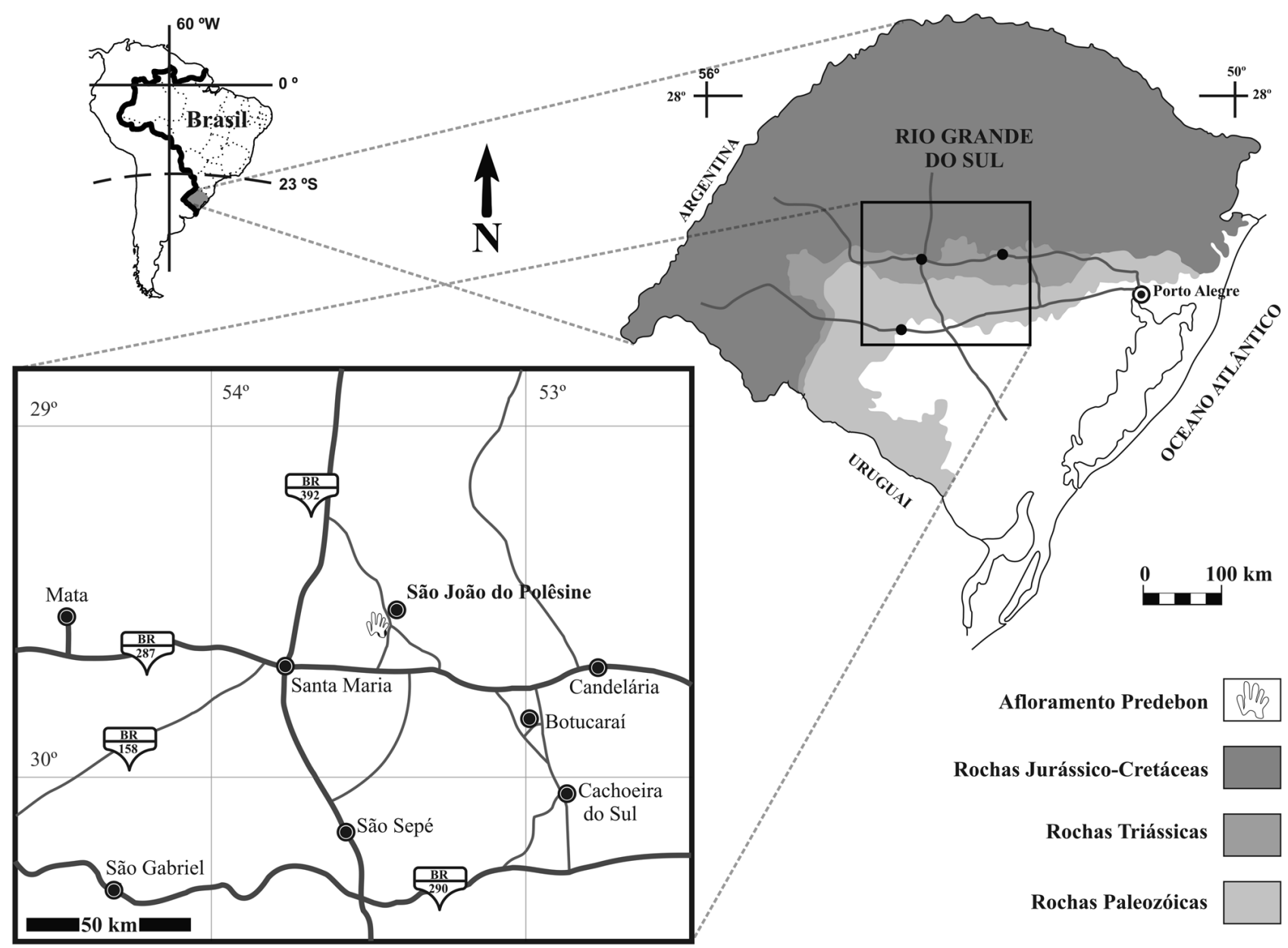

Figura 1 - Localização do afloramento Predebon, Formação Santa Maria (Triássico, Bacia do Paraná), Município de São João do Polêsine, Estado do Rio Grande do Sul, Brasil. 
seguintes parâmetros (baseados em Leonardi 1987): comprimento da pegada (C), largura da pegada (L), comprimento da planta (CP), largura da planta (LP), comprimento dos dígitos (CDI, CDII, CDIII, CDIV, CDV), divergência interdigital (DI-II, DII-III, DIII-IV, DIV-V), divergência total (DT), distância intermanus ou interpedes (DI), ângulo do passo (AP), passo oblíquo (PO), meio passo (MP), passo duplo (PD) e distância mão-pé (DMP). Foram mensuradas duas pistas das amostras MCN.PIC.017 e MCN.PIC.018, resultando em 16 pegadas de mãos e 10 pegadas de pés. Esses dados permitiram a realização de uma análise estatística simples, com o objetivo de caracterizar morfometricamente o material estudado.

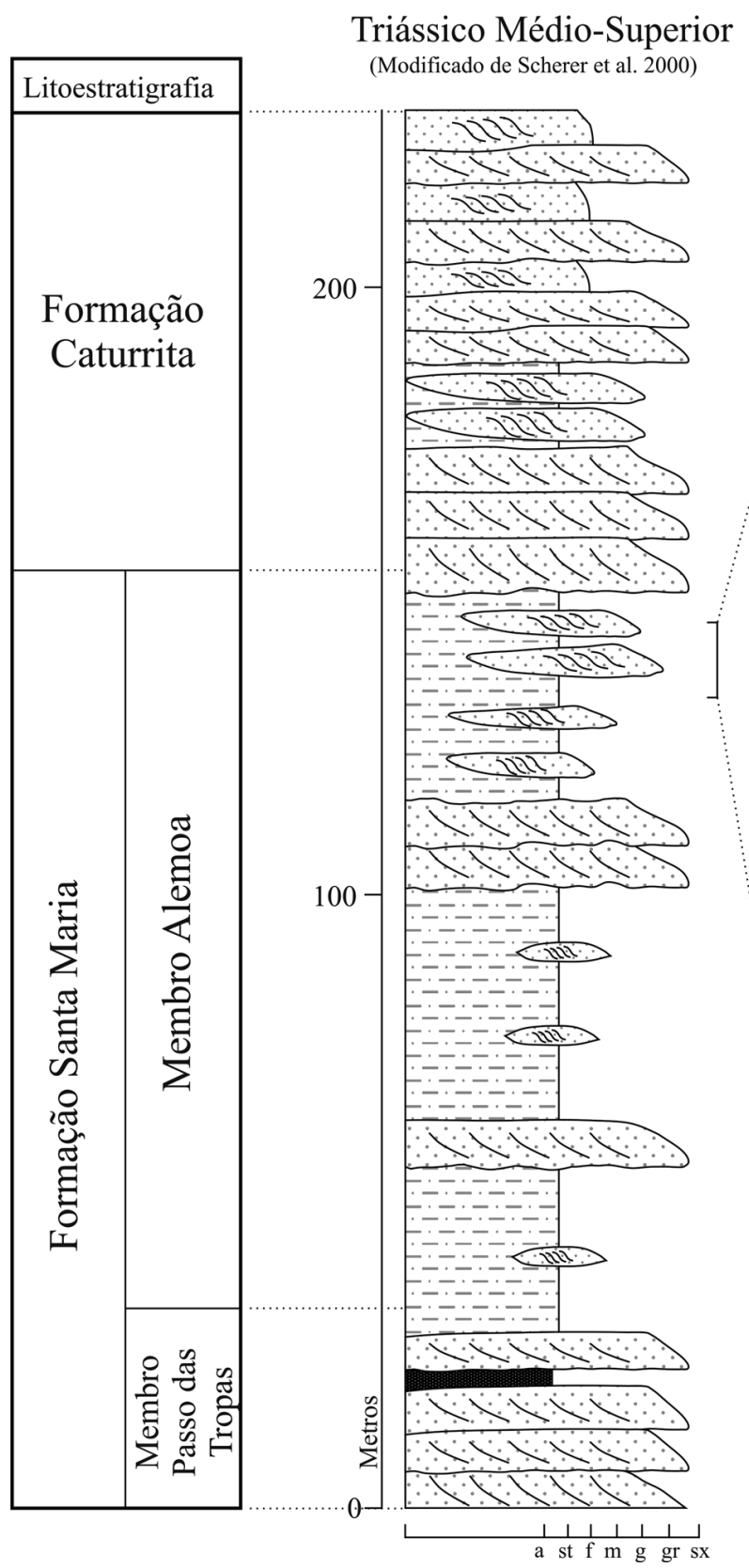

CONTEXTO GEOLÓGICO A Formação Santa Maria (Triássico Médio-Superior) integra o Grupo Rosário do Sul (Bacia do Paraná), que abrange ainda as formações Sanga do Cabral (Triássico Inferior) e Caturrita (sensu Andreis et al. 1980, Triássico Superior), todas restritas ao Estado do Rio Grande do Sul (Milani et al. 1994, Schneider et al. 1974).

A Formação Santa Maria (Fig. 2) originou-se em um sistema deposicional continental flúvio-lacustre (Faccini 1989, Zerfass et al. 2003, Da-Rosa 2005) e é dividida nos membros Passo das Tropas e Alemoa (Andreis et al. 1980). O primeiro, mais basal, é formado por conglomerados e arenitos grossos, correspondendo a um sistema fluvial entrelaçado, efêmero e de alta

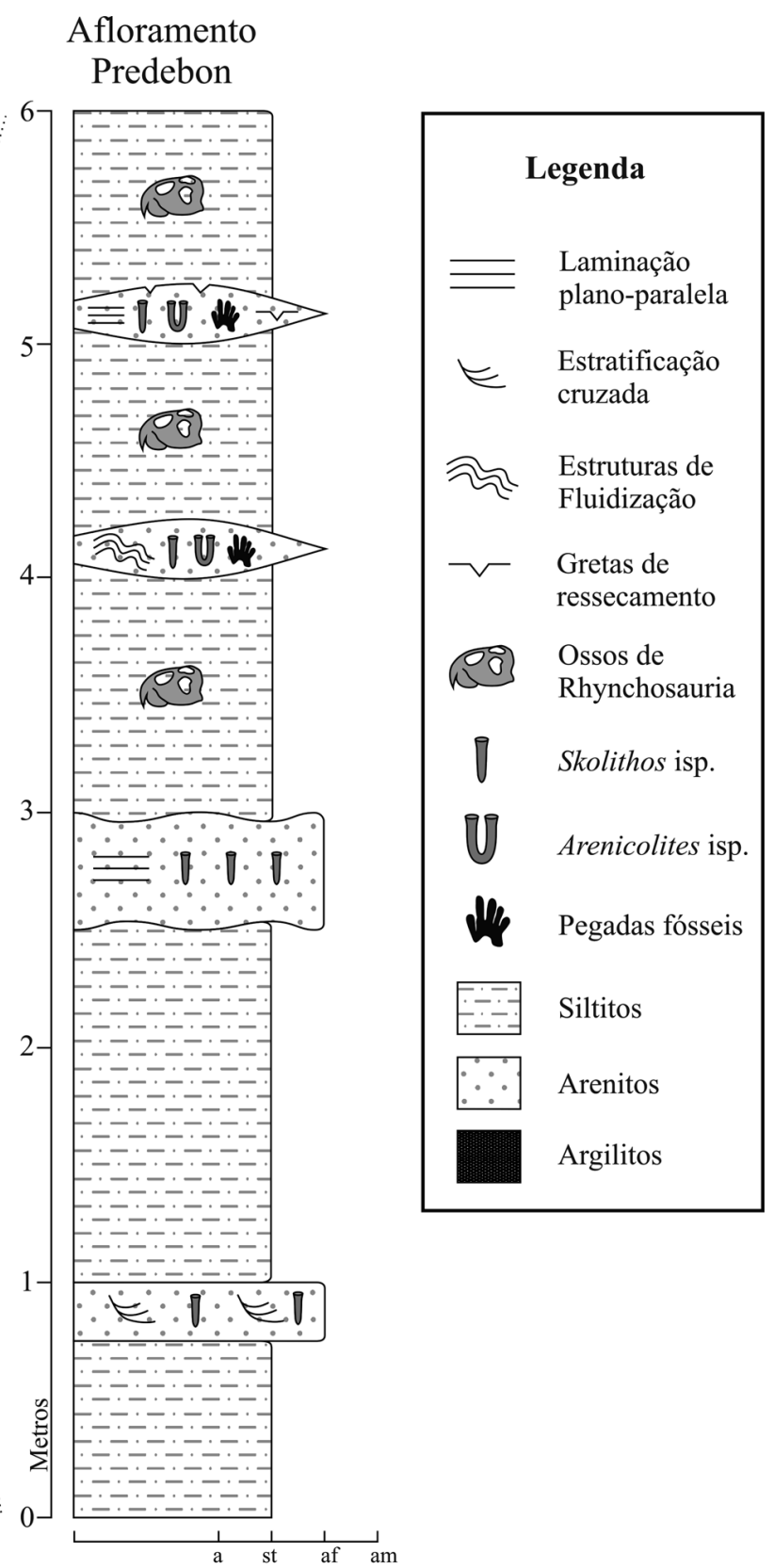

Figura 2 - Seção composta das formações Santa Maria e Caturrita (Triássico, Bacia do Paraná) e seção detalhada do afloramento Predebon. 
energia (Faccini 1989, Zerfass et al. 2003). Os arenitos são lenticulares, com estratificações cruzadas acanaladas de pequeno a médio porte e laminações plano-paralelas. O Membro Alemoa, superior, é caracterizado por pelitos avermelhados, maciços ou finamente laminados, intercalados com siltitos e arenitos finos, níveis de calcretes e paleosolos (Faccini 1989, Zerfass et al. 2003, Da-Rosa 2005). No topo deste membro, os pelitos são intercalados com arenitos tabulares e lenticulares finos a médios, ricos em intraclastos esbranquiçados, com laminação horizontal e climbing ripples (Schultz et al. 2000). Estes depósitos podem ser inclusos na Superseqüência Gondwana II, distribuída temporalmente entre o Triássico Médio e Superior (Milani 2002). Diversos autores estudaram anteriormente a seqüência AlemoaCaturrita e não há consenso em relação à sua idade, mas todos parecem concordar em uma idade carniana para o topo da Formação Santa Maria (e.g. Scherer et al. 2000, Rubert \& Schultz 2004, Lucas 1998, 2001, Lucas \& Heckert 2002, Langer 2005).

O afloramento Predebon (Fig. 2), situado no Município de São João do Polêsine (RS), apresenta cerca de 100 metros de extensão e seis metros de altura e é constituído por duas sucessões distintas. A sucessão inferior estende-se até a metade da altura do afloramento e é caracterizada por arenitos finos siltosos, quartzosos, avermelhados e tabulares intercalados por camadas centimétricas de siltitos também avermelhados, maciços ou com estratificação plano-paralela pouco distinta. Os arenitos tabulares apresentam estratificação planoparalela e são ricos em icnitos de escavação verticais. A sucessão superior é constituída por um depósito de pelito maciço avermelhado cortado por camadas lenticulares de arenito siltoso e quartzoso com pouco mais de um metro de extensão lateral. Estas lentes apresentam estratificação plano-paralela e níveis com gretas de ressecamento bastante finas, além de estruturas de fluidização. As pegadas fósseis, raras no afloramento, ocorrem nestas camadas lenticulares.

\section{ICNOLOGIA SISTEMÁTICA}

Dicynodontipus Rühle von Liliestern 1944

Diagnose Pegadas plantígradas, pentadáctilas, com contorno arredondado, aproximadamente simétricas, mesaxônicas ou ligeiramente ectaxônicas, com prevalência funcional da palma. A planta é elíptica, sendo o eixo transversal maior que o longitudinal, e pode apresentar uma projeção posterior arredondada. Os dígitos são curtos e seu tamanho aumenta ligeiramente do I ao IV, sendo o V menor.

Icnoespécie tipo Dicynodontipus geinitzi (Hornstein 1876).

\section{Dicynodontipus isp.}

Material MCN.PIC.001/12-16 (Fig. 3A), MCN. PIC.002/11-14 (Fig. 3B), MCN.PIC.003/16-19 (Fig. 3C), MCN.PIC.004/15-16 (Fig. 4A) e MCN.PIC.019/1-
11 (Fig. 4B), pistas em hiporrelevo convexo; MCN. PIC.018-1 (Fig. 5), molde e contramolde.

Descrição Pegadas teromorfóides isoladas ou formando pistas incompletas, aproximadamente simétricas, pentadáctilas, mesaxônicas, preservadas em hiporrelevo convexo. Pode haver leve escalonamento proporcionado não pelo tamanho crescente dos dígitos e sim pela posição do eixo metapódio-falangeal. Os dígitos são largos e curtos em relação à planta ou palma, com extremidades agudas. Os hypexes são levemente arredondados. Não ocorrem almofadas falangeais, mas há impressões de almofadas palmares ou plantares, sendo uma almofada arredondada posterior a cada dígito. A planta é tão longa quanto larga, com formato ovalado e uma pequena projeção digitiforme posterior. As pistas são bastante irregulares com pegadas alternadas pouco nítidas. Em muitas das pegadas são preservados apenas três ou quatro dígitos. A planta ou palma pode não ocorrer ou estar preservada com forma arredondada. A bitola da pista é bastante estreita, com altos ângulos de passo.

Discussão O material estudado difere dos icnotáxons teromorfóides ou mamalóides Dicynodontipus protherioides isp. nov. e Ameghinichnus Casamiquela 1964 pela presença de uma planta grande com projeção posterior. Entretanto, assemelha-se à icnoespécie Dicynodontipus bellambiensis Retallack 1996, descrito para o Triássico Inferior da Antártica, pela presença de dígitos mais estreitos com extremidades agudas, diferindo do mesmo por não apresentar uma grande divergência interdigital entre os dígitos IV e V. O material estudado difere também de Dicynodontipus icelsi Klerk 2002, com pegadas que ultrapassam 20 centímetros de comprimento, pela evidente diferença de dimensões. Assemelha-se a $D$. geinitzi (Hornstein 1876), comum em rochas triássicas européias, pela forma da palma ou planta e posição da inserção dos dígitos, mas não apresenta características suficientes para uma atribuição a essa icnoespécie. De acordo com as características morfológicas, o material estudado pode ser atribuído ao icnogênero Dicynodontipus. Devido à escassez de espécimes não é possível atribuir essas pegadas a nenhuma das demais icnoespécies de Dicynodontipus, sendo usada então a denominação Dicynodontipus isp. Uma hipótese a ser considerada é que essas pegadas constituam variações preservacionais, comportamentais ou populacionais de Dicynodontipus protherioides isp. nov., mas até o momento não há evidências suficientes que a confirmem.

\section{Dicynodontipus protherioides isp. nov}

Material MCN-PIC.007/17-23, pista em epirrelevo côncavo (superfície superior); MCN-PIC.016/1-21 (Fig. 4C), amostra com uma pista formada por 21 pegadas e pequenas marca de arraste de cauda preservada em hiporrelevo convexo (superfície inferior); MCNPIC.017/1-18 (Fig. 6), amostra com uma pista formada por 18 pegadas preservadas em hiporrelevo convexo (superfície inferior), com marca de arraste de cauda e 

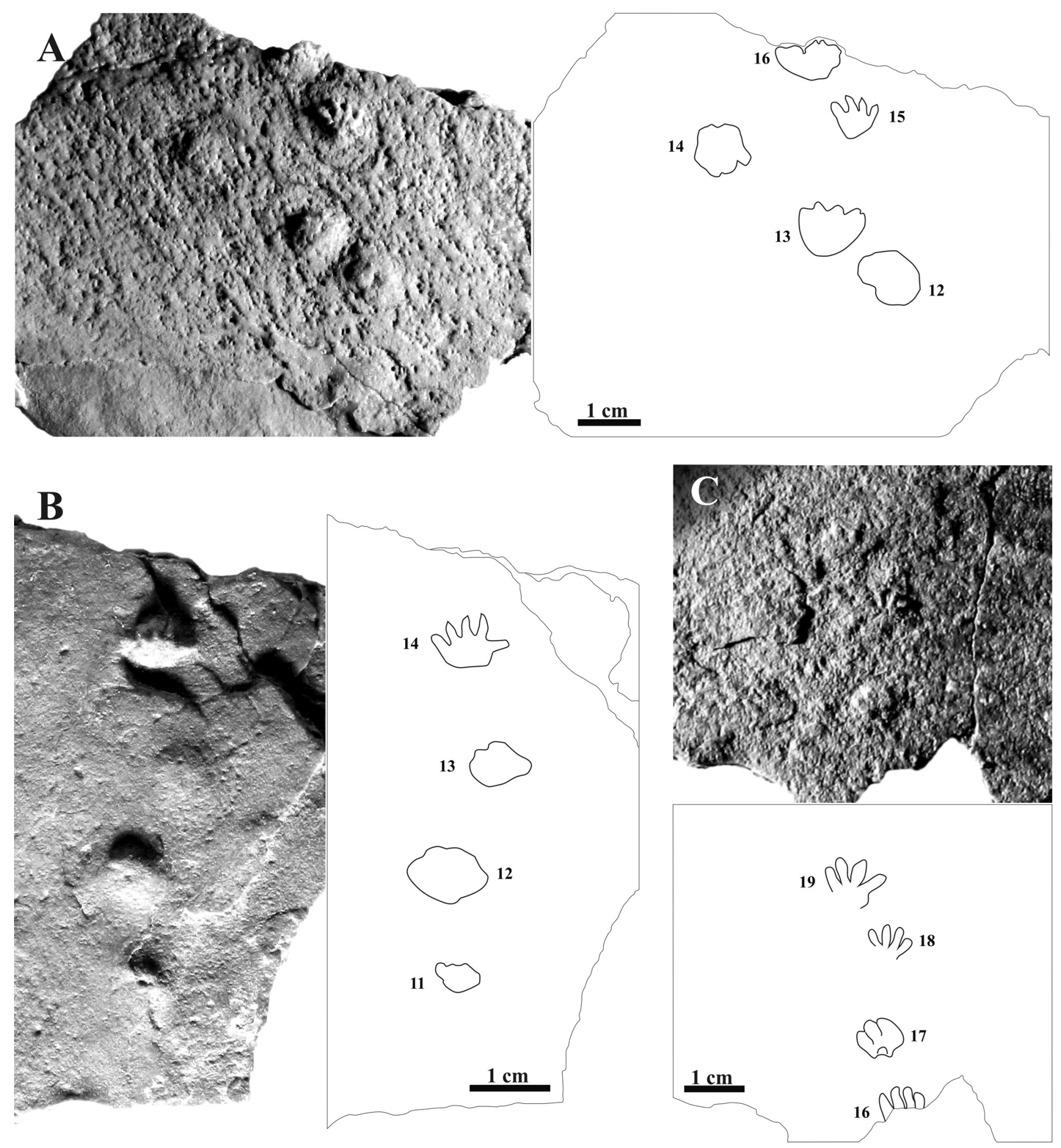

Figura 3 - Pegadas teromorfóides, Dicynodontipus isp., da Formação Santa Maria: A) Amostra MCN.PIC.001; B) Amostra MCN.PIC.002; C) Amostra MCN.PIC.003.

gretas de ressecamento; MCN-PIC.018/2-16 (Fig. 5), duas amostras (molde e contramolde) com uma pista formada por quinze pegadas e uma marca de arraste de cauda preservadas em epirrelevo côncavo (superfície superior) e hiporrelevo convexo (superfície inferior).

Holótipo MCN-PIC.017/1-18, pista em hiporrelevo convexo.
Parátipos MCN-PIC.016/1-21, pegadas isoladas em hiporrelevo convexo; MCN-PIC.018/2-16, pista em hiporrelevo convexo.

Diagnose Pegadas plantígradas a semiplantígradas, levemente assimétricas e mesaxônicas a ectaxônicas. Apresentam quatro a cinco dígitos curtos (em relação à planta ou palma) com leve escalonamento progressivo dos dígitos I a IV, que são separados do dígito $\mathrm{V}$ por um 

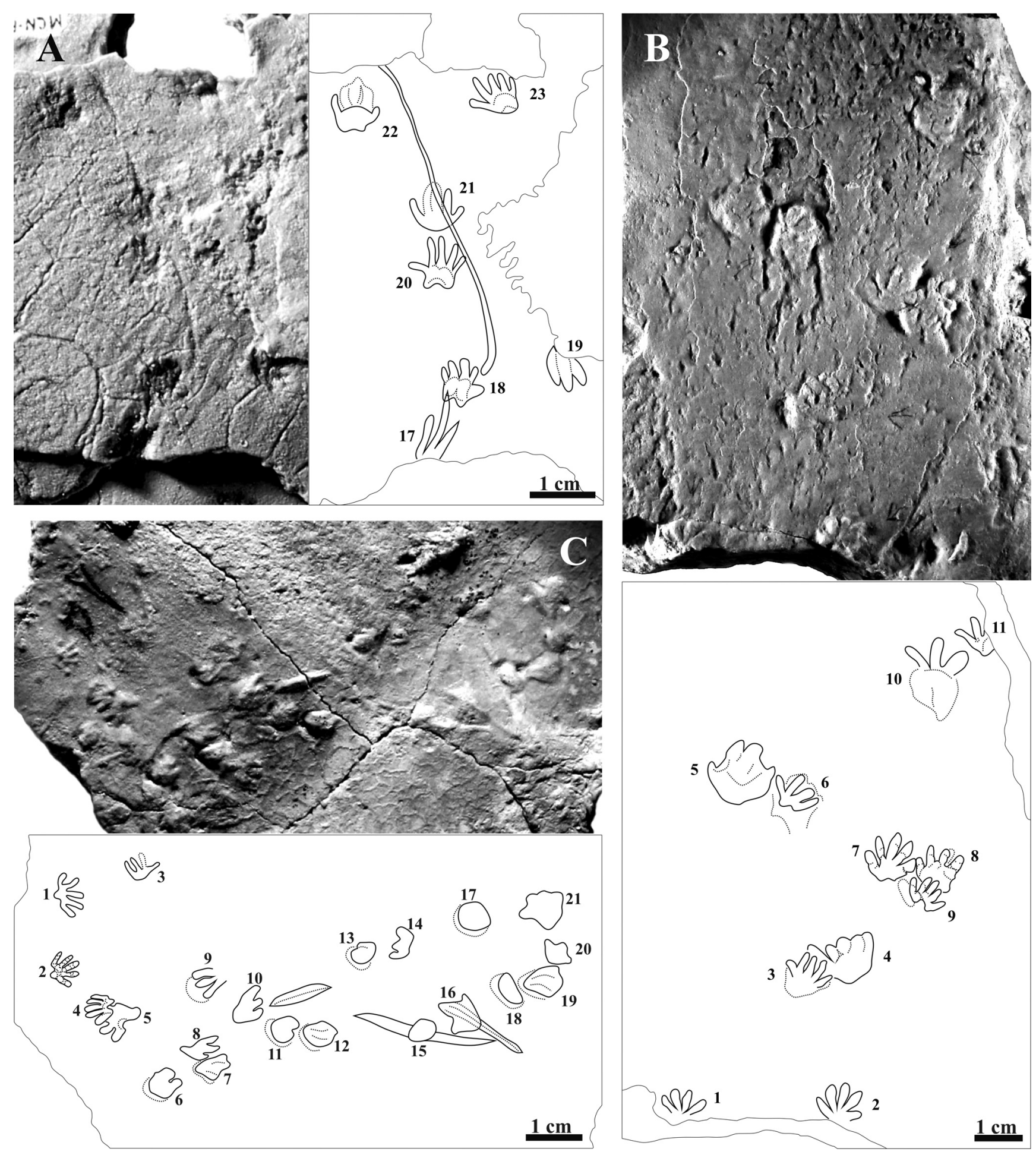

Figura 4 - Pegadas teromorfóides da Formação Santa Maria: A) Dicynodontipus isp., amostra MCN.PIC.004; B) Dicynodontipus isp., amostra MCN.PIC.019; C) Dicynodontipus protherioides isp. nov., amostra MCN.PIC.016, parátipo.

ângulo interdigital ligeiramente maior. Palma ou planta apresentam forma de meia lua com concavidade voltada posteriormente, com uma almofada palmar/plantar para cada dígito. A pista apresenta andar caminhado e alternado com mão anterior e medial em relação ao pé no conjunto mão-pé, sem sobreposição ou ultrapassa- gem, associada a marca de arraste de cauda intermitente, retilínea a ligeiramente sinuosa.

Etimologia Pro, ancestral; therio (therium), besta, geralmente usado para mamíferos; oide, com forma semelhante a. 

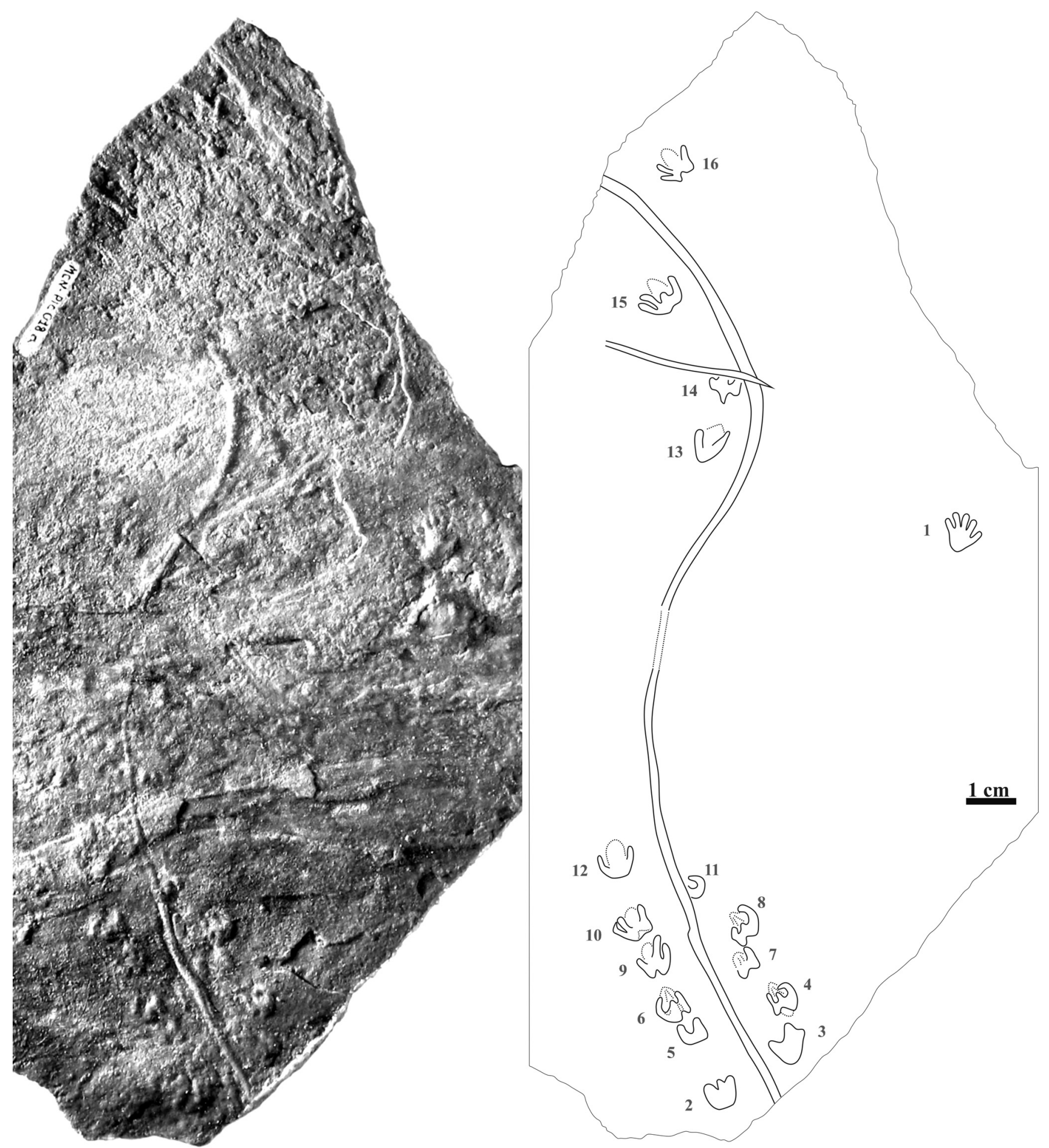

Figura 5 - Pegadas teromorfóides da Formação Santa Maria, Dicynodontipus protherioides isp. nov., amostra MCN.PIC.018a, parátipo.

Descrição Todas as pegadas observadas ocorrem preservadas como hiporrelevo convexo. As pistas indicam andar caminhado com conjuntos mão-pé alternados, estando associadas a uma marca de arraste de cauda irregular e descontínua, retilínea a ligeiramente sinuosa com a parte interna da curva medial ao conjunto mão-pé; a mão é anterior e medial em relação ao pé no conjunto mão-pé; não ocorre sobreposição ou ultrapassagem. A pegada MCN.PIC.017/2 é a que melhor representa as características da mão, sendo assimétrica, pentadáctila, ectaxônica, plantígrada, com leve escalonamento dos dígitos I a IV e dígito V menor que o IV e com inserção mais posterior, mas não separado dos demais; a palma apresenta um formato aproximadamente retangular com cantos arredondados e um entalhe no bordo posterior; os dígitos I a IV inserem-se ao longo do bordo anterior e o dígito $\mathrm{V}$ no bordo lateral; os hypexes e as extremidades dos dígitos são arredondados; é possível distinguir 


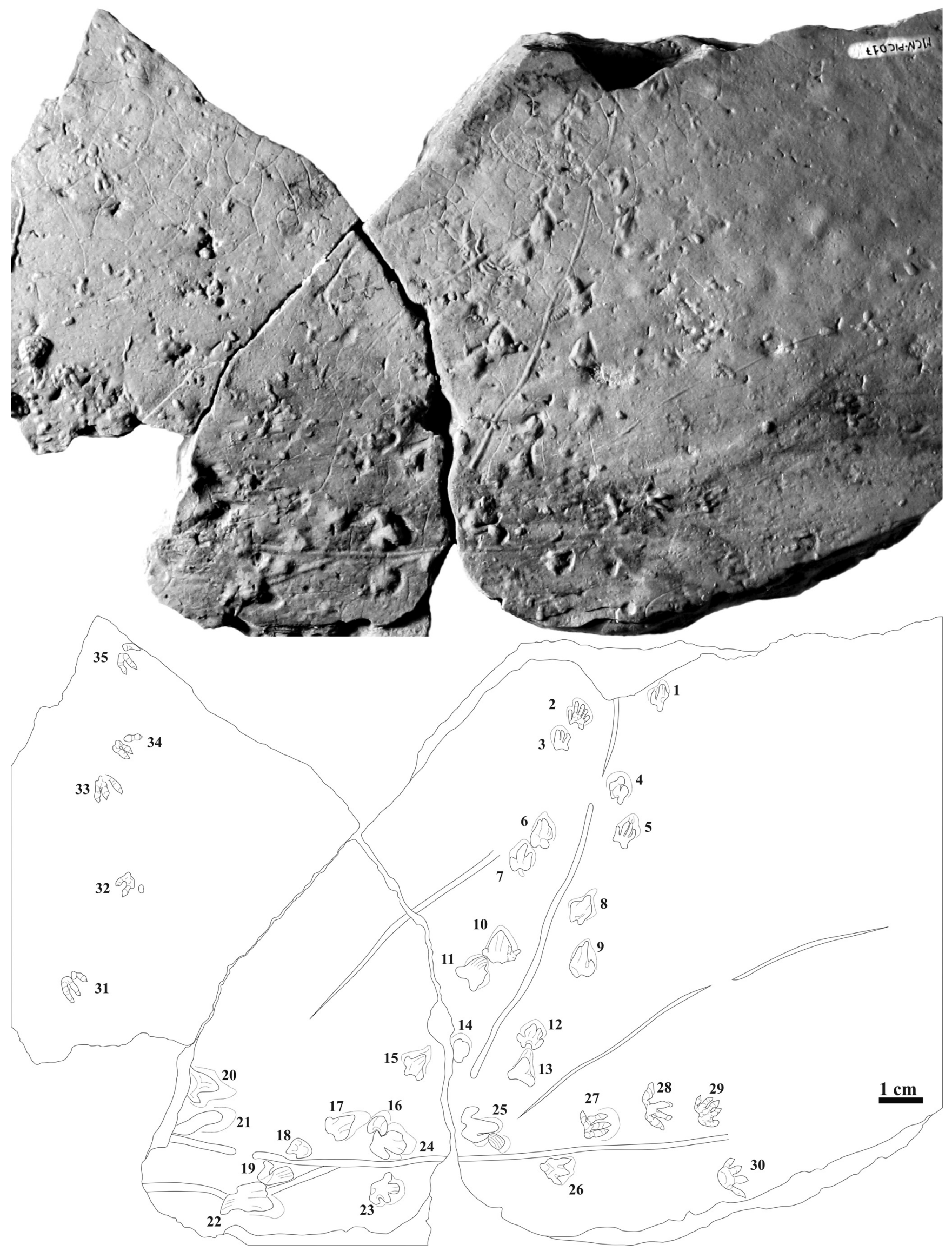

Figura 6 - Pegadas teromorfóides da Formação Santa Maria, Dicynodontipus protherioides isp. nov., amostra MCN.PIC.017, holótipo. 
duas almofadas falangeais no dígito II, três do dígito III e duas no dígito IV, além de almofadas palmares arredondadas nas bases dos dígitos I, III e IV. A pegada MCN.PIC.017/5 representa melhor as características do pé, sendo assimétrica, ectaxônica, plantígrada, com quatro dígitos preservados, sendo os dígitos II e III mais alongados; a planta apresenta um formato retangular com cantos arredondados e um entalhe arredondado no bordo posterior, sendo que os dígitos I a IV inserem-se ao longo do bordo anterior; os hypexes e as extremidades dos dígitos são arredondados; não é possível distinguir almofadas falangeais ou plantares, mas as pegadas MCN.PIC.017/6, MCN.PIC.017/8, MCN.PIC.017/9 e MCN.PIC.017/15 apresentam impressões de almofadas palmares/plantares, e a pegada MCN.PIC.017/10 apresenta duas ou três impressões de almofadas falangeais no dígito I. Não há diferença nas dimensões entre as pegadas das mãos e dos pés. A preservação dos dígitos é bastante variável dentre as amostras observadas, podendo apresentar apenas dois ou três dígitos ou ocorrer sob a forma de uma impressão com contorno arredondado. As pegadas MCN.PIC.017/6-10, MCN. PIC.017/13, MCN.PIC.017/15 e MCN.PIC.017/17 apresentam um contorno aproximadamente triangular com três impressões digitiformes preservadas de forma pouco nítida, sendo a central mais alongada e a lateral mais curta; a impressão central pode apresentar duas ou mais estrias longitudinais; a porção correspondente à palma ou planta apresenta um entalhe arredondado no bordo posterior; os hypexes e extremidades dos dígitos são arredondados e a divergência interdigital é pequena. As pegadas MCN.PIC.017/1 e MCN.PIC.017/7 apresentam uma pequena projeção voltada posteriormente no entalhe da planta. Todas as pegadas da pista MCN. PIC.017/1-18, exceto a MCN.PIC.017/18, apresentam um bordo de deformação de sedimento elevado (relevo positivo na superfície original) anteriormente a elas. As pegadas MCN.PIC.017/19-30 formam outra pista que cruza e sobrepõe a pista MCN.PIC.017/1-18. Na amostra MCN.PIC.016 ocorrem 21 pegadas sem o padrão característico de uma pista, com relevo bastante suave. As pegadas MCN.PIC.016/1-5 são pentadáctilas, mesaxônicas a ectaxônicas, plantígradas a semi-plantígradas com tubérculos digitais terminais. Na pegada MCN. PIC.016/2, os dígitos II a IV apresentam comprimento semelhante são separados dos dígitos I e V por um ângulo interdigital ligeiramente maior que entre os dígitos II, III e IV; os tubérculos terminais podem ser melhor visualizados nessa pegada. As pegadas MCN.PIC.016/1 e MCN.PIC.016/5 apresentam uma pequena projeção posterior da palma/planta. A pista MCN-PIC.007/17-23 é composta por sete pegadas e uma marca de arraste de cauda levemente sinuosa que corta a pegada MCNPIC.007/21; a preservação é bastante precária, mas é possível observar o padrão do conjunto mão-pé sendo a mão anterior e levemente medial em relação ao pé; as pegadas MCN-PIC.007/18, MCN-PIC.007/20 e MCNPIC.007/23 apresentam cinco dígitos preservados, sem garras, com escalonamento pouco evidente. A pista MCN.PIC.018/2-16 apresenta uma pista característica, com padrão caminhado e alternado associada a marca de arraste de cauda, porém, com todos os valores relativos ao passo menores que na pista MCN.PIC.017/118; as pegadas encontram-se pobremente preservadas, havendo preservação preferencial dos dígitos mais laterais e mediais e do contorno posterior da palma/planta. As medidas das pegadas e pistas de Dicynodontipus protherioides isp. nov encontram-se na tabela 1.

Discussão O material estudado apresenta semelhanças com alguns icnogêneros tradicionalmente atribuídos a terapsídeos ou mamíferos basais. Segundo Hunt et al. (1993), o icnogênero Dicynodontipus Rühle von Liliestern 1944 é o icnotáxon melhor conhecido e mais representativo dentre aqueles atribuídos a Therapsida. Este apresenta diversas semelhanças com o material estudado, tais como a presença pegadas plantígradas/palmígradas, aproximadamente simétricas, mesaxônicas ou ligeiramente ectaxônicas, com prevalência funcional da planta/palma, com leve escalonamento dos dígitos I ao IV, planta larga e curta com projeção posterior, sendo o eixo transversal maior que o longitudinal, e preservação freqüente de apenas quatro dígitos, especialmente em D. geinitzi (Hornstein 1876) e D. icelsi Klerk 2002. Dessa forma, as pegadas estudadas podem ser atribuídas ao icnogênero Dicynodontipus. As várias espécies conhecidas de Dicynodontipus diferem do material estudado por várias características: D. icelsi apresenta grandes dimensões, sendo os dígitos com garras, curtos em relação à palma/planta; $D$. bellambiensis Retallack 1996 apresenta dígitos afilados com base larga e extremidade aguda, pouca diferenciação entre os dígitos e a palma/planta é de tamanho maior; $D$. geinitzi apresenta pegadas com maiores dimensões, planta elíptica e grande em relação aos dígitos, sendo que estes não possuem tubérculos terminais (e.g. Conti et al. 1977, Leonardi et al. 2002). Sendo assim, o material estudado pode ser atribuído a uma espécie nova. Dicynodontipus protherioides isp. nov. assemelha-se a Ameghinichnus Casamiquela 1964, icnogênero tipicamente jurássico presente na Argentina e África do Sul (Casamiquela 1964, Olsen \& Galton 1984), por apresentar pista com mãos mais próximas à linha média em relação aos pés, freqüente sobreposição parcial das mãos pelos pés, almofadas plantares e palmares, dígitos com tubérculos terminais e marca de cauda sinuosa. Entretanto, Ameghinichnus apresenta algumas características não compartilhadas com Dicynodontipus protherioides isp. nov., tais como a presença de planta e palma mais curtas sem projeção posterior, autopódios digitígrados a semi-digitígrados, pistas de andar caminhado e ricochete com ultrapassagem dos pés em relação às mãos e dígitos I e $\mathrm{V}$ separados dos demais por um ângulo maior que entre II, III e IV, sendo estes do mesmo comprimento. As duas últimas características podem ser observadas também em Cynodontipus polythrix Ellenberger 1976 e na pegada isolada MCN.PIC.016-2, sendo possível que representem variações comportamentais dos animais produtores e não necessariamente anatômicas. As pegadas do icnogênero Cynodontipus diferem de Dicynodontipus pro- 
Tabela 1 - Dicynodontipus protherioides isp. nov. Parâmetros das pistas.

\begin{tabular}{|c|c|c|c|c|c|c|c|c|c|c|c|}
\hline & & $\mathrm{C}$ & $\mathrm{L}$ & $\mathrm{CP}$ & LP & CDI & CDII & CDIII & CDIV & $\mathrm{CDV}$ & DMP \\
\hline \multirow{4}{*}{ 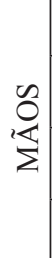 } & Média & 0,63 & 0,62 & 0,36 & 0,28 & 0,22 & 0,26 & 0,30 & 0,31 & 0,27 & 0,87 \\
\hline & Mediana & 0,60 & 0,61 & 0,27 & 0,26 & 0,23 & 0,27 & 0,30 & 0,31 & 0,27 & 0,80 \\
\hline & Desvio Padrão & 0,08 & 0,12 & 0,18 & 0,06 & 0,03 & 0,03 & 0,02 & 0,02 & 0,02 & 0,18 \\
\hline & C. de Variação & 12,70 & 19,35 & 50,00 & 21,43 & 13,63 & 11,54 & 6,45 & 6,45 & 7,41 & 20,69 \\
\hline \multirow{4}{*}{ 哇 } & Média & 0,69 & 0,57 & 0,28 & 0,38 & 0,29 & 0,37 & 0,31 & 0,29 & 0,28 & \\
\hline & Mediana & 0,64 & 0,59 & 0,28 & 0,38 & 0,29 & 0,37 & 0,31 & 0,29 & 0,28 & \\
\hline & Desvio Padrão & 0,13 & 0,13 & - & - & 0,07 & 0,10 & 0,07 & 0,02 & - & \\
\hline & C. de Variação & 18,84 & 22,80 & - & - & 20,14 & 27,03 & 22,58 & 6,70 & - & \\
\hline \multirow{5}{*}{$\sum_{i}^{\infty}$} & & DI-II & DII-III & DIII-IV & DIV-V & DT & DI & AP & $\mathrm{PO}$ & MP & PD \\
\hline & Média & 36,22 & 21,40 & 13,07 & 19,59 & 82,25 & 1,62 & 74,36 & 2,05 & 1,18 & 2,40 \\
\hline & Mediana & 35,69 & 22,73 & 12,27 & 21,10 & 76,31 & 1,47 & 82,13 & 2,11 & 1,13 & 2,49 \\
\hline & Desvio Padrão & 21,69 & 9,82 & 2,35 & 5,67 & 36,03 & 0,26 & 20,26 & 0,15 & 0,29 & 0,51 \\
\hline & C. de Variação & 59,88 & 45,89 & 17,98 & 28,94 & 43,80 & 16,05 & 27,25 & 7,32 & 24,58 & 21,25 \\
\hline \multirow{4}{*}{ 氠 } & Média & 9,98 & 11,00 & 9,65 & - & 60,10 & 1,87 & 66,26 & 2,23 & 1,24 & 2,44 \\
\hline & Mediana & 9,98 & 11,00 & 9,65 & - & 60,10 & 2,02 & 64,72 & 2,46 & 1,23 & 2,54 \\
\hline & Desvio Padrão & 2,07 & 3,03 & 3,47 & - & - & 0,32 & 7,61 & 0,40 & 0,24 & 0,55 \\
\hline & C. de Variação & 20,74 & 27,54 & 35,96 & - & - & 17,11 & 11,48 & 17,94 & 19,35 & 22,54 \\
\hline
\end{tabular}

therioides isp. nov. por apresentar maiores dimensões, chegando a $25 \mathrm{~cm}$ de comprimento. Algumas pegadas de C. polythrix apresentam evidências da presença de pêlos no animal produtor (Ellenberger 1976). As pegadas do icnogênero Therapsipus Hunt Santucci Lockley \& Olson, 1993, cuja única icnoespécie é T. cumminsi, são atribuídas a dicinodontes, mas também diferem de Dicynodontipus protherioides isp. nov. por apresentar planta grande em relação aos dígitos e grandes dimensões (Hunt et al. 1993). O icnogênero Procolophonichnium Nopcsa 1923 apresenta algumas semelhanças com Dicynodontipus protherioides isp. nov., tais como presença de escalonamento digital e padrão de andadura, porém o escalonamento é mais acentuado, as pegadas são digitígradas, a planta é estreita sem projeção posterior e ocorrem garras curvadas lateralmente (e.g. Holst et al. 1970, Diedrich 2000, Diedrich 2002); as pegadas do icnogênero Procolophonichnium tendem a ser digitígradas mesmo em diferentes teores de umidade (Diedrich 2002). As pegadas da icnoespécie Dicynodontipus protherioides isp. nov. apresentam algumas semelhanças com Varanopus microdactylus (Pabst 1896), tais como pista com padrão alternado, mão an- terior ao pé no conjunto mão-pé e planta alongada em relação aos dígitos. Entretanto, este apresenta escalonamento digital mais pronunciado e dígitos mais longos, com garras curvadas medialmente. A icnoespécie $V$. microdactylus é atribuída a Procolophonidae ou Captorhinidae (Haubold 1971), e essas semelhanças poderiam representar uma convergência de hábitos. O material estudado apresenta ainda algumas poucas semelhanças com pegadas mamalóides tais como Gallegosichnus garridoi Casamiquela 1964 e Calibarichnus ayestarani Casamiquela 1964, do Mesozóico da Argentina, tais como dígitos com pequena divergência interdigital e planta larga com uma projeção posterior (Casamiquela 1964). Pegadas atribuídas ao icnogênero Dicynodontipus são comuns em rochas do Permiano e Triássico do hemisfério norte, principalmente Europa e América do Norte, mas ocorrem também no Permiano Superior brasileiro, na Formação Rio do Rasto (Leonardi et al. 2002), e Triássico Médio argentino, na Formação Cerro de las Cabras (Marsicano et al. 2004).

\section{Incertae sedis}




\section{Material MCN.PIC.017/20-35 (Fig. 6).}

Descrição As pegadas MCN.PIC.017/20-30 formam outra pista que cruza e sobrepõe a pista MCN. PIC.017/1-18. A pista MCN.PIC.017/20-30 é bastante irregular e sem padrão definido, ocorrendo associada a uma marca de arraste de cauda aproximadamente retilínea e descontínua. Não é possível definir seguramente quais pegadas correspondem a pés ou a mãos. As pegadas MCN.PIC.017/20, MCN.PIC.017/24 e MCN. PIC.017/25 consistem em formas irregulares contendo três impressões digitiformes, sendo que a central é mais longa e a lateral mais curta e separada das demais por um maior ângulo; os hypexes e extremidades dos dígitos são arredondados e a divergência interdigital pequena; a impressão central na pegada MCN.PIC.017/24 é bastante larga e ocorrem estrias longitudinais. Na pegada MCN.PIC.017/25 é possível observar um pequeno entalhe posterior; essa pegada ocorre associada a uma impressão arredondada e estriada que não pode ser associada com certeza à pista. A pegada MCN.PIC.017/21 consiste em uma impressão alongada e levemente sinuosa, sem maiores detalhes morfológicos. A pegada MCN.PIC.017/22 sobrepõe a marca de arraste de cauda da pista MCN.PIC.017/1-18 e consiste em uma impressão aproximadamente retangular com uma larga projeção posterior; ao longo da pegada ocorrem estrias longitudinais. A pegada MCN.PIC.017/23 constitui uma impressão irregular com quatro dígitos e uma palma/ planta aproximadamente quadrada; o dígito mais lateral insere-se no bordo lateral da palma/planta, enquanto os demais dígitos inserem-se em seu bordo anterior; os dígitos apresentam extremidades e hypexes arredondados. As pegadas MCN.PIC.017/26-30 apresentam detalhes morfológicos mais claros. A pegada MCN.PIC.017/26 apresenta três dígitos de comprimento semelhante associados a uma planta/palma mais larga que longa, que apresenta uma projeção posterior; os dois dígitos mais mediais apresentam extremidades agudas, mas todos os hypexes são arredondados. A pegada MCN.PIC.017/27 é mesaxônica a ectaxônica, semiplantígrada e apresenta os dígitos II a V preservados; os dígitos II a IV apresentam comprimento semelhante e encontram-se voltados anteriormente; o dígito $\mathrm{V}$ é menor e separados dos demais por um maior ângulo interdigital, inserindo-se lateralmente à pegada; ocorrem três almofadas falangeais no dígito II, três no dígito III, quatro no dígito IV e duas no dígito II; todos terminam em garras e apresentam hypexes arredondados. A pegada MCN.PIC.017/28 é semelhante à anterior, mas apresenta maior divergência interdigital e total. A pegada MCN.PIC.017/29 apresenta uma palma/planta mais larga que longa e cinco dígitos preservados com leve escalonamento do dígito I ao III; o dígito I é curto e apresenta extremidade arredondada, os demais dígitos são terminados em garras; os hypexes são levemente arredondados; o dígito $\mathrm{V}$ insere-se lateral e posteriormente à palma/planta; ocorrem duas a três almofadas falangeais em cada dígito e duas almofadas palmares/plantares posteriores à cada dígito, exceto o dígito V. A pegada MCN.PIC.017/30 apresen- ta forma semelhante à ultima, mas com quatro dígitos preservados. As pegadas da pista MCN.PIC.017/31-35, embora estejam preservadas de forma mais superficial, mostram características morfológicas semelhantes à pegada MCN.PIC.017/27, sendo tridáctilas, mesaxônicas, com dígitos aproximadamente do mesmo comprimento e terminados em garras; os hypexes são arredondados e ocorrem duas a três almofadas falangeais em cada dígito. O padrão de andadura não é reconhecível.

Discussão A maioria das pegadas da pista MCN. PIC.017/20-35 apresenta poucas características que permitam uma identificação icnotaxonômica ou do animal produtor. As pegadas MCN.PIC.017/26-27 apresentam características em comum com o icnogênero Rotodactylus Peabody 1948 e Neorotodactylus Casamiquela 1980, tais como a presença de três dígitos de comprimento semelhante associados a um dígito lateral ou revertido. As pegadas MCN.PIC.017/29-30 têm algumas semelhanças com os icnogêneros Dicynodontipus e $C y$ nodontipus, como a presença de palma/planta grande em relação aos dígitos, mais larga que longa e dígitos com leve escalonamento do I ao IV, sendo o dígito $\mathrm{V}$ inserido lateralmente. Assim, não é possível conhecer a afinidade taxonômica ou morfológica dessas pegadas, $\mathrm{o}$ que justifica sua classificação como Incertae sedis.

DISCUSSÃO As pegadas estudadas apresentam algumas características preservacionais que, apesar de serem típicas de subpegadas (e.g. Lockley 2000), tais como digitigradia e redução do número de dígitos, podem ser interpretadas como variações na plasticidade do sedimento, tal como observado por Silva et al. (2007b). Algumas características, como a presença de marcas de arraste de cauda e almofadas falangeais, são um indicativo de que as superfícies com pegadas correspondem às originais (Swanson \& Carlson 2002, Milàn e Bromley 2006). Além disso, muitas das pegadas estudadas apresentam bordos elevados de sedimento preservados como hiporrelevo côncavo produzidos durante o movimento de retração do apêndice locomotor. Estas estruturas não podem ser preservadas como subpegadas visto que não são produzidas por carga ou disruptura no substrato e conseqüentemente não afetam camadas abaixo da superfície.

As amostras MCN.PIC.016, MCN.PIC.017 e MCN.PIC.018, contendo pegadas e pistas de Dicynodontipus protherioides isp. nov., são semelhantes em relação às características preservacionais. Embora o padrão das pistas seja facilmente reconhecido, a maioria das pegadas encontra-se deformada pela plasticidade do sedimento. A planta é geralmente reconhecível, mas em poucas pegadas os dígitos podem ser individualizados e sua presença é caracterizada pela ocorrência de estrias longitudinais nas pegadas. Freqüentemente as pegadas apresentam um bordo de sedimento anterior, convexo no relevo original, formado pelo deslocamento do autopódio no sedimento plástico. As pegadas dos pés apresentaram preservação menos detalhada que das mãos, sendo que em nenhuma delas foi possível observar a 
série digital completa. As pegadas das amostras MCN. PIC.016 e MCN.PIC.017 encontram-se associadas a gretas de ressecamento pequenas e pouco profundas, que estendem-se apenas parcialmente sobre a superfície, evidenciando que houve alguma exposição subaérea antes do soterramento. A amostra MCN.PIC.018 apresenta sua superfície sulcada por pequenas marcas de escoamento de água, maiores nas regiões onde pegadas não estão preservadas, mostrando que a pista original foi parcialmente destruída pelo fluxo de água em sua porção média, restando apenas vestígios da marca de arraste de cauda.

As pegadas atribuídas a Dicynodontipus isp. apresentam-se precariamente preservadas, ocorrendo com freqüência sob a forma de impressões arredondadas. Nenhum padrão regular ou completo de pista foi observado, sendo assim impossível distinguir pegadas de pés ou mãos. Em alguns casos apenas os dígitos foram preservados, como nos exemplares MCN.PIC.004/1516. Esses fatores impediram que as mensurações fossem efetuadas. É possível que as pistas teromorfóides presentes nas amostras MCN.PIC.001, MCN.PIC.002 e MCN.PIC.003 correspondam à porção da pista produzida por um lado do corpo, sendo que a outra metade não teria sido preservada. As amostras MCN.PIC.001, MCN.PIC.002, MCN.PIC.003 e MCN.PIC.004 apresentam também em sua superfície superior, preservadas como epirrelevo côncavo, pegadas lacertóides citadas por Silva et al. (2007a, 2008). Curiosamente, estas pegadas coincidem em direção e sentido com as pegadas do icnogênero Dicynodontipus que ocorrem na superfície inferior (Fig. 7), indicando que, embora as amostras não se encaixem, as pistas em epirrelevo correspondem a uma seqüência produzida por um único animal lacertóide ao passo que as pistas em hiporrelevo possivelmente foram produzidas pelo mesmo animal teromorfóide, havendo uma pequena diferença temporal entre a passagem deles. Possíveis explicações para essa coincidência seriam a presença de obstáculos que obrigariam os animais a seguirem o mesmo caminho ou a ocorrência de um ponto de travessia mais fácil através do terreno encharcado.

As condições de preservação das pegadas fósseis do afloramento Predebon foram estudadas anteriormente por Silva et al. (2007a, 2008), que as classificaram em cinco estágios diferentes em relação ao conteúdo ou nível d'água no momento em que foram produzidas e à posterior exposição subaérea: pegadas subaquáticas (lâmina d'água de poucos centímetros, sem exposição subaérea); pegadas semi-aquáticas (pequena lâmina d'água, exposição subaérea mínima); pegadas semi-terrestres (lâmina d'água mínima, exposição subaérea moderada); pegadas em substrato encharcado (sedimento encharcado e muito plástico, exposição subaérea moderada); pegadas em substrato úmido (sedimento úmido e pouco plástico, exposição subaérea prolongada). Formas semelhantes de preservação foram descritas por Diedrich $(2000,2002)$. Os icnofósseis analisados no presente trabalho podem ser classificados dentre as pegadas em substrato encharcado devido

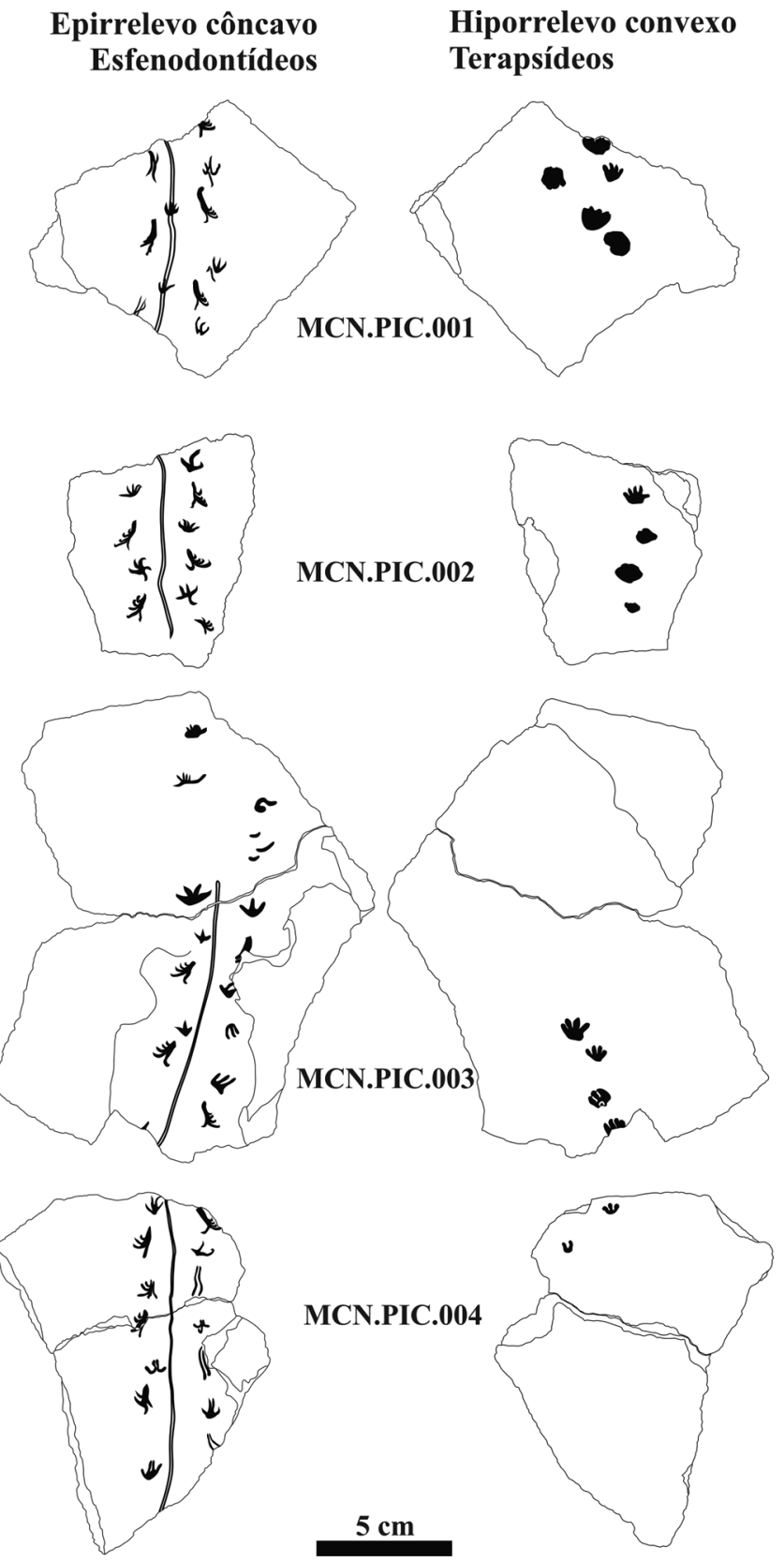

Figura 7 - Amostras MCN.PIC.001, 002, 003 e 004 mostrando pistas lacertóides em epirrelevo e teromorfóides em hiporrelevo, com a mesma orientação.

à presença de marcas de arraste de cauda intermitentes e gretas de ressecamento cobrindo parcialmente a superfície, além de marcas produzidas por fluxo d'água. Pegadas com características análogas foram produzidas experimentalmente por Brand $(1979,1996)$ em substratos com propriedades semelhantes. Segundo Silva et al. (2007b), a preservação das pegadas do afloramento Predebon ocorreu como resultado de três etapas: (1) as pegadas foram produzidas tanto em sedimento encharcado; (2) com a diminuição do nível d'água, a superfície secou de forma diferencial, ficando levemente endurecida; (3) as pegadas foram soterradas por uma fina camada de areia, com baixa energia. Pegadas com 
feições preservacionais semelhantes ocorrem em rochas do Grupo Beaufort (Permiano Superior, África do Sul) em um contexto de planície de inundação (Smith 1993), apresentando pegadas terrestres e semi-aquáticas associadas a gretas de ressecamento.

A análise estatística de Dicynodontipus protherioides isp. nov. (Tab. 1) revelou que a média e a mediana apresentam valores muito próximos, constituindo bons representantes da população estudada mesmo com uma amostragem relativamente baixa (Leonard 1987). As medidas das mãos apresentaram coeficientes de variação mais baixos que as dos pés, exceto pelos parâmetros DI-II, DII-III, AP e MP. Em relação às mãos, de um modo geral, as medidas angulares mostraram maior variação que as medidas lineares, em especial nos ângulos entre os dígitos mais externos. A mensuração dos dígitos foi possível em um número menor de pegadas dos pés e praticamente não há variação entre as medidas angulares e lineares. Os parâmetros das pistas também apresentaram coeficientes de variação relativamente baixos, mostrando que, apesar de terem sido mensuradas duas pistas diferentes, o tipo de andadura é consistente e possivelmente representa a andadura mais comum do animal produtor.

A distância gleno-acetabular (DGA) do produtor de Dicynodontipus protherioides isp. nov. foi calculada com a fórmula DGA $=3 / 4 \mathrm{PD}+\mathrm{DMP}(\mathrm{PD}=$ passo duplo, DMP = distância mão-pé), levando-se em consideração a presença de um padrão alternado das pistas sem sincronia dos autopódios do mesmo par diagonal (Leonardi 1987), sendo que o valor obtido foi de 2,68 $\mathrm{cm}$. As pegadas descritas por Retallack (1996) como Dicynodontipus bellambiensis apresentam tanto andar alternado, típico de tetrápodes basais, como andar esquipado, mais característico de mamíferos e alguns dinossauros saurópodes (Leonardi 1987, Casanovas et al. 1997), mostrando que ambos os padrões estavam presentes dentre os terapsídeos. $\mathrm{O}$ padrão alternado também ocorre em Therapsipus cumminsi (Hunt et al. 1993), icnoespécie atribuída a grandes dicinodontes. O comprimento total do corpo não pode ser estimado com segurança; alguns autores consideram que este corresponde ao dobro do valor do comprimento glenoacetabular no caso de animais lacertóides (e.g. Leonardi 1987). É possível que este valor, em torno de 5,36 $\mathrm{cm}$, seja próximo do comprimento real do corpo dos animais produtores de Dicynodontipus protherioides isp. nov. A presença de uma marca de arraste de cauda retilínea ou levemente sinuosa indica que o animal se deslocava com um mínimo de flexão lateral da coluna vertebral. Reconstruções esqueletais de cinodontes como Thrinaxodon mostram que o animal apresentava postura semi-ereta, tronco relativamente longo em comparação com o comprimento total do corpo, cauda curta e autopódios plantígrados (Jenkins1971). Este padrão morfológico do corpo coincide com o esperado para os animais produtores de Dicynodontipus protherioides isp. nov. As pistas estudadas foram produzidas por andar caminhado, visto que os passos são regulares e curtos; além disso, há preservação preferencial das plantas e palmas dos autopódios, o que não ocorreria caso o animal estivesse se deslocando com andar corrido. É possível inferir ainda, pela bitola relativamente larga da pista e pela presença de autopódios palmígrados a semipalmígrados e plantígrados a semiplantígrados, que o animal teria postura semi-ereta e seria possivelmente cursorial e de hábitos terrestre (Fig. 8).

De acordo com as características encontradas, é possível relacionar Dicynodontipus protherioides isp. nov. com as ocorrências de cinodontes avançados de pequeno porte, baseadas em esqueletos fossilizados, preservados em rochas de idade semelhante, embora seja impossível definir diretamente qual espécie produziu as pegadas. As rochas da seqüência Alemoa-Caturrita apresentam diversas ocorrências de cinodontes, vários deles de pequeno porte tais como Therioherpeton cargnini (Bonaparte \& Barberena 1975, 2001, Oliveira 2006), Riograndia guaibensis (Bonaparte et al. 2001), Irajatherium hernandezi (Martinelli et al. 2005), Protheriodon estudianti (Bonaparte et al. 2006), Charruodon tetracuspidatus (Abdala \& Ribeiro 2000), Brasilodon quadrangularis e Brasilitherium riograndensis (Bonaparte et al. 2003). Apesar da razoável quantidade de táxons conhecidos, ainda há poucas informações acerca do pós-crânio desses animais; entretanto, é interessante observar que há vários animais que poderiam ter produzido as pegadas de Dicynodontipus protherioides isp. nov.

A porção superior do Membro Alemoa da Formação Santa Maria, na qual se insere o afloramento Predebon, é rica em fósseis de rincossauros, constituindo assim a Fauna Local de Alemoa (Barberena 1977), inclusa na Cenozona de Rhynchosauria (Schultz et al. 2000). Este membro é correlacionável à Formação Ischigualasto, do Triássico da Argentina (e.g. Barberena 1977, Bonaparte 1982, Schultz et al. 2000). Embora o registro osteológico do afloramento Predebon seja condizente com a fauna conhecida para o Membro Alemoa, a icnofauna deste afloramento é mais semelhante à fauna da Formação Caturrita, que apresenta registros ósseos de esfenodontídeos (Ferigolo 1999, 2000), além dos cinodontes (possivelmente tritelodontídeos) de pequeno porte. Considerando a seqüência Alemoa-Caturrita como concordante e contínua (Schultz et al. 2000), a diferença temporal entre a icnofauna do afloramento Predebon e a fauna da Formação Caturrita seria de pouca importância. É relativamente comum que ocorrências icnológicas antecipem os primeiros registros osteológicos de grupos animais ao longo do tempo geológico (Lockley 1991, Sarjeant 1988). Isso deve-se ao fato de que quanto maior for a população de determinada espécie, maiores as chances de fossilização de indivíduos desta espécie, visto tratar-se de um evento raro. Já a preservação de pegadas, embora seja fortemente limitada pelas condições ambientais e de sedimentação, não necessita de populações bem estabelecidas para que ocorra, visto que apenas um indivíduo pode produzir milhares de pegadas passíveis de preservação durante a sua vida, mas deixar apenas um esqueleto. 


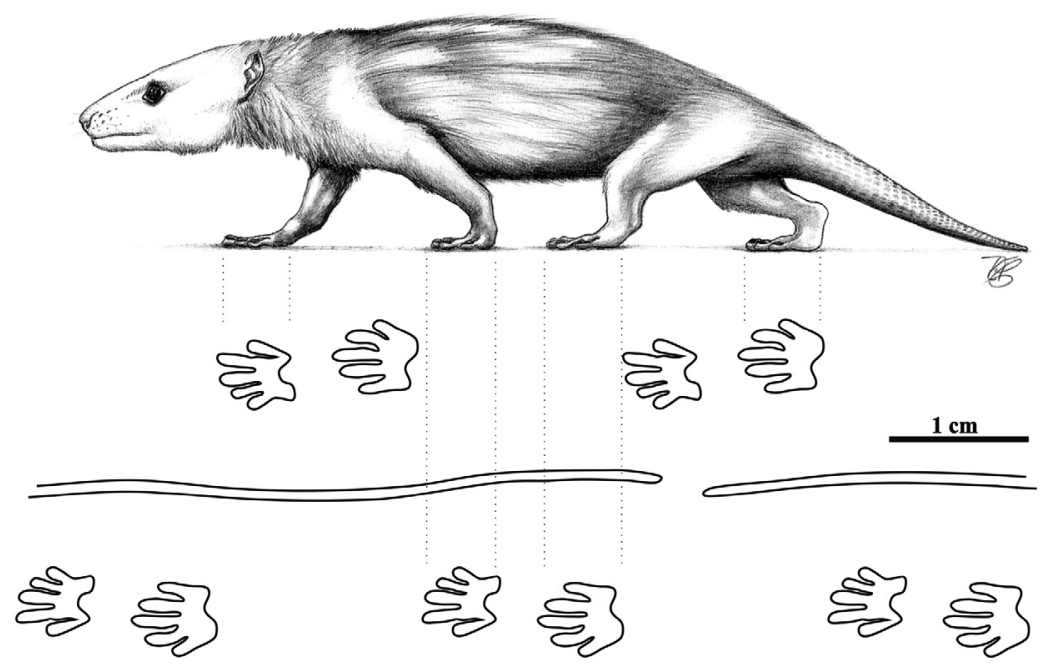

Figura 8 - Reconstrução da pista de Dicynodontipus protherioides isp. nov. com base nas médias dos parâmetros morfométricos mensurados e reconstituição do animal produtor (desenho de Renata Cunha).

CONCLUSÕES (1) As pegadas teromorfóides da Formação Santa Maria podem ser inseridas em dois icnotáxons distintos, Dicynodontipus protherioides isp. nov. e Dicynodontipus isp.; outras pegadas encontradas associadas a estas não apresentam características suficientes para uma identificação confiável, sendo assim classificadas como Incertae sedis;

(2) As pegadas foram produzidas em sedimento fino, plástico e encharcado, tendo ocorrido um breve período de exposição aérea posterior, conferindo o endurecimento da superfície e permitindo assim a sua preservação;

(3) O produtor de Dicynodontipus protherioides isp. nov. corresponde a um animal quadrúpede, cursorial, com andar alternado mas pouca flexão lateral da coluna vertebral; a postura era semi-ereta e os autopódios palmígrados/plantígrados a semipalmígrados/ semiplantígrados, sem garras longas e agudas e com almofadas falangeais e plantares/palmares. As pistas foram produzidas com andar caminhado e com a cauda tocando o chão.

(4) As pegadas estudadas, incluindo Dicynodontipus protherioides isp. nov. e Dicynodontipus isp., podem ser atribuídas a cinodontes avançados de pequeno porte, possivelmente tritelodontídeos, cujos esqueletos são encontrados nas formações Santa Maria e Caturrita, embora a associação com pegadas de esfenodontídeos torne essa icnocenose mais semelhante à paleofauna da Formação Caturrita.

Agradecimentos À Dra ${ }^{\mathrm{a}}$. Ana Maria Ribeiro (Museu de Ciências Naturais, Fundação Zoobotânica do Rio Grande do Sul) pelo auxílio com o material; ao Dr. Ricardo Negri pela participação nos trabalhos de campo; ao Dr. Henrique Zerfass e Companhia de Pesquisa de Recursos Minerais (CPRM) pelas críticas, elaboração da seção estratigráfica do afloramento Predebon e apoio nos trabalhos de campo concomitantes com o mapeamento geológico da área realizado pela instituição mencionada; à $\mathrm{Dr}^{\mathrm{a}}$. Cibele Schwanke (Universidade do Estado do Rio de Janeiro) e ao MSc. Fernando A. Sedor (Universidade Federal do Paraná) pelas críticas; à Renata Cunha pela reconstrução artística na figura 8; ao Sr. Albino João Predebon, proprietário da área onde se situa o afloramento; o apoio financeiro ao desenvolvimento deste estudo foi realizado através do $\mathrm{CNPq}$ (Conselho Nacional de Desenvolvimento Científico e Tecnológico, bolsa n ${ }^{\circ}$ E-26/152.541/2006), FAPERJ (Fundação Carlos Chagas Filho de Amparo à Pesquisa no Estado do Rio de Janeiro) e CAPES (Coordenação de Aperfeiçoamento de Pessoal de Nível Superior).

\section{Referências}

Abdala F. \& Ribeiro A.M. 2000. A new therioherpetid cynodont from the Santa Maria Formation (middle Late Triassic), southern Brazil. Geodiversitas, 22:589-596.

Abramoff M.D., Magelhaes P.J., Ram S.J. 2004. Image Processing with ImageJ. Biophotonics International, 11:3642.

Andreis R.R., Bossi G.E., Montardo D.K. 1980. O Grupo
Rosário do Sul (Triássico) no Rio Grande do Sul - Brasil. In: SBG, Congr. Bras. Geol., 31, Camboriú, Anais, 2:659-673.

Barberena M.C. 1977. Bioestratigrafia preliminar da Formação Santa Maria. Pesquisas, 7:111-129.

Bonaparte J.F. 1982. Faunal replacement in the Triassic of South America. Journal of Vertebrate Paleontology, 
2:362-371.

Bonaparte J.F. \& Barberena M.C. 1975. A possible mammalian ancestor from the middle Triassic of Brazil, Therapsida-Cynodontia. Journal of Paleontology, 49:931-936.

Bonaparte J.F. \& Barberena M.C. 2001. On two advanced carnivorous cynodonts from the Late Triassic of southern Brazil. Bulletin of the Museum of Comparative Zoology, 156:59-80.

Bonaparte J.F., Ferigolo J., Ribeiro A.M. 2001. A primitive Late Triassic 'ictidosaur' from Rio Grande do Sul, Brazil. Palaeontology, 44:623-635.

Bonaparte J.F., Martinelli A.G., Schultz C.L., Rubert R. 2003. The sister group of mammals: small cynodonts from the Late Triassic of Southern Brazil. Revista Brasileira de Paleontologia, 5:5-27.

Bonaparte J.F., Soares M.B., Schultz C.L. 2006. A new non-mammalian cynodont from the Middle Triassic of Southern Brazil and its implications for the ancestry of mammals. In: Harris J.D., Lucas S.G., Spielmann J.A., Lockley M.G., Milner A.R.C., Kirkland J.I. (eds.) The Triassic-Jurassic Terrestrial Transition. New Mexico Museum of Natural History and Science Bulletin, 37:599-607.

Brand L.R. 1979. Field and laboratory studies on the coconino sandstone (Permian) vertebrate footprints and their paleoecological implications. Palaeogeography, Palaeoclimatology, Palaeoecology, 28:25-38.

Brand L.R. 1996. Variations in salamander trackways resulting from substrate differences. Journal of Paleontology, 70:1004-1010.

Casamiquela R.M. 1964. Estudios Icnológicos. Buenos Aires, Colegio Industrial Pio IX, 229 p.

Casamiquela R.M. 1980. Nuevos argumentos en favor de la transferencia de Rotodactylus, icno-genero reptiliano, de los "crocodiloides" (Archosauria) a los "lacertoides" (incertae sedis). Ameghiniana, 17:121-129.

Casanovas M., Fernández A., Pérez-Lorente F., Santafé J.V. 1997. Sauropod trackways from site El Sobaquillo (Munilla, La Rioja, Spain) indicate amble walking. Ichnos, 5:101-107.

Conti M.A., Leonardi G., Mariotti N., Nicosia U. 1977. Tetrapod footprints of the "Val Gardena Sandstone" (North Italy). Their paleontological, stratigraphic and paleoenvironmental meaning. Palaeontographia Italica, 70:191.

Da-Rosa A.A.S. 2005. Paleoalterações em depósitos sedimentares de planícies aluviais do Triássico Médio a Superior do sul do Brasil: caracterização, análise estratigráfica e preservação fossilífera. Tese de Doutorado, Universidade do Vale do Rio dos Sinos, São Leopoldo, Brasil, $211 \mathrm{p}$.

Diedrich C. 2000. Neue Wirbeltierfährten aus dem Unteren Muschelkalk (Mitteltrias) des Osnabrücker Berglandes and Teutoburger Waldes (NW-Deutschland) und ihre stratigraphische und paläeogeographische Bedeutung im Germanischen Becken. Neues Jarbuch für Geologie und Paläeontologie, 217:369-395.

Diedrich C. 2002. Vertebrate track bed stratigraphy at new megatrack sites in the Upper Wellenkalk Member and orbicularis Member (Muschelkalk, Middle Triassic) in carbonate tidal flat environments of the western Germanic Basin. Palaeogeography, Palaeoclimatology, Palaeoecology, 183:185-208.

Ellenberger P. 1976. Une piste avec traces de soies é paisses dans le trias inférieur a moyen de Lodève (Héralt, France): Cynodontipus polythrix nov. gen., nov. sp. Les Cynodontes em France. Geobios, 9:769-787.

Faccini U.F. 1989. O Permo-Triássico do Rio Grande do Sul. Uma análise sob o ponto de vista das seqüências deposicionais. Dissertação de Mestrado, Universidade Federal do Rio Grande do Sul, Curso de Pós-Graduação em Geociências, Porto Alegre, Brasil, 121 p.

Fernandes A.C.S., Borghi L., Carvalho I.S., Abreu C.J. 2002. Guia dos Icnofósseis de Invertebrados do Brasil. Rio de Janeiro, Interciência, 260 p.

Ferigolo J. 1999. South-american first record of a sphenodontian (Lepidosauria, Rhynchocephalia) from Late Triassic-Early Jurassic of Rio Grande do Sul State, Brazil. In: International Symposium on Mesozoic Terrestrial Ecosystem, 7, Buenos Aires, Abstracts, vol. 1, p.24.

Ferigolo J.2000. Esfenodontídeos do Neo-triássico/?Jurássico do Estado do Rio Grande do Sul. In: Holz M. \& De Ros L.F. (eds.) Paleontologia do Rio Grande do Sul. Porto Alegre, CIGO/UFRGS, p. 236-245.

Haubold H. 1971. Die tetrapodenfährten aus dem Permosiles (Stefan und Rotliegendes) des Thüringer Waldes. Abhandlungen und Berichte des Museums der Natur Gotha, S:15-59.

Holst H.K.H., Smit J., Veenstra E. 1970. Lacertoid footprints from the early Middle Triassic at Haarmühle, near Alstätte, W. Germany. Proceedings of the Koninklijke Nederlandse Akademie van Wetenschappen, Sect. B 73:157165.

Hornstein F. 1876. Letter to H. B. Geinitz on a new species of Chirotherium. Neües Jahrbuch fur Mineralogie, Geologie und Palaontologie, p. 933.

Hunt A.P., Santucci V.L., Lockley M.G., Olson T.J. 1993. Dicynodont trackways from the Holbrook Member of the Moenkopi Formation (Middle Triassic: Anisian), Arizona, USA. In: Lucas S.G. \& Morales M. (eds.) The Nonmarine Triassic. New Mexico Museum of Natural History \& Science Bulletin, 3:213-218.

Jenkins F.A. 1971. The postcranial skeleton of African cynodonts. Bulletin Peabody Museum (Nat. Hist.), 36:1-216.

Klerk W.J. 2002. A dicynodont trackway from the Cistecephalus assemblage zone in the Karoo, east of Graaff-Reinet, South Africa. Palaeontologia Africana, 38:73-91.

Langer M.C. 2005. Studies on continental Late Triassic tetrapod biochronology. I. The type locality of Saturnalia tupiniquim and the faunal succession in south Brazil. Journal of South American Earth Sciences, 19:205-218.

Leonardi G. (ed.) 1987. Glossary and manual of Tetrapod footprint Palaeoichnology. DNPM, Brasília, 117 p.

Leonardi G., Sedor F.A., Costa R. 2002. Pegadas de répteis terrestres na Formação Rio do Rasto (Permiano Superior da Bacia do Paraná), Estado do Paraná, Brasil. Arquivos do Museu Nacional, 60:213-216.

Lockley M.G. 1991. Tracking Dinosaurs. Cambridge University Press, Cambridge, 238 p.

Lockley M.G. 2000. Permian perambulations become "un- 
derstandable". Ichnos, 7:161-168.

Lucas S.G. 1998. Global Triassic tetrapod biostratigraphy and biochronology. Palaeogeography, Palaeoclimatology, Palaeoecology, 143:347-384.

Lucas S.G. 2001. Age and correlation of Triassic tetrapod assemblages from Brazil. Albertiana, 26:13-20.

Lucas S.G. \& Heckert, A.B. 2002. The Hyperodapedon Biochron, Late Triassic of Pangea. Albertiana, 27:30-38.

Marsicano C.A., Arcucci A.B., Mancuso A., Caselli A.T. 2004. Middle Triassic tetrapod footprints of southern South America. Ameghiniana, 41:171-184.

Martinelli A.G., Bonaparte J.F., Schultz C.L., Rubert R. 2005. A new tritheledontid (Therapsida, Eucynodontia) from the Late Triassic of Rio Grande do Sul (Brazil) and its phylogenetic relationships among carnivorous nonmammlain eucynodonts. Ameghiniana, 42:191-208.

Milàn J. \& Bromley R.G. 2006. True tracks, undertracks and eroded tracks, experimental work with tetrapod tracks in laboratory and field. Palaeogeography, Palaeoclimatology, Palaeoecology, 231:253-264.

Milani E.J. 2002. Geodinâmica fanerozóica do Gondwana sul-ocidental e a evolução geológica da Bacia do Paraná. In: Holz M.e De Ros L.F. (eds.) Geologia do Rio Grande do Sul. CIGO/UFRGS, Porto Alegre, p. 275-302.

Milani E.J., França A.B., Schneider R.L. 1994. Bacia do Paraná. Boletim de Geociências da PETROBRÁS, 8:69-82.

Oliveira E.V. 2006. Reevaluation of Therioherpeton cargnini Bonaparte \& Barberena, 1975 (Probainognathia, Therioherpetidae) from the Upper Triassic of Brazil. Geodiversitas, 28:447-465.

Olsen P.E. \& Galton P.M. 1984. A review of the Reptile and Amphibian Assemblages from the Stormberg of Southern Africa, with special emphasis on the footprints and age of the Stormberg. Palaeontologia Africana, 25:87110.

Pabst W. 1896. Tierfährten aus dem Oberrotliegenden von Tambach in Thüringen. Zeitschrift der Deutschen Geologischen Gesellschaft, 48:638-643.

Peabody F.E. 1948. Reptile and Amphibian trackways from the Lower Triassic Moenkopi Formation of Arizona and Utah. University of California Bulletin of Geological Science, 27:295-468.

Retallack G.J. 1996. Early Triassic therapsid footprint from the Sydney Basin, Australia. Alcheringa, 20:301-314.

Rigby J.K. \& Clark D.L. 1965. Casting and molding. In: B. Kummel e D. Raup (eds.) Handbook of Paleontological Techniques, W.H. Freeman and Company, San Francisco, p. 389-413.

Rubert R.R. \& Schultz C.L. 2004. Um novo horizonte de correlação para o Triássico Superior do Rio Grande do Sul. Pesquisas em Geociências, 31:71-88.

Rühle von Lilienstern H. 1939. Faehrten und Spurenim Chirotherium Sandstein von Suedthueringen. Fortschritte zur Geologie und Palaeontologie, 12:293-389.

Rühle von Lilienstern H. 1944. Eine Dicynodontierfährte aus dem Chirotheriumsandstein von Hessberg. Paläontologische Zeitschrift, 23:368-385.

Sarjeant W.A.S. 1988. Fossil vertebrate footprints. Geology Today, 4:125-130.

Scherer C.M.S., Faccini U.F., Lavina E.L. 2000. Arcabouço estratigráfico do Mesozóico da Bacia do Paraná. In: Holz M. \& De Ros L.F. (eds.) Geologia do Rio Grande do Sul. CIGO/UFRGS, Porto Alegre, p. 335-354.

Schneider R.L., Mülmann H., Tommasi E., Medeiros R.A., Daemon R.F., Nogueira A.A. 1974. Revisão estratigráfica da Bacia do Paraná. In: Congr. Bras. Geol., 28, Porto Alegre, Anais, vol.1, p.41-65.

Schultz C.L., Scherer C.M.S., Barberena M.C. 2000. Bioestratigraphy of Southern Brazilian Middle-Upper Triassic. Revi. Brasileira de Geociências, 30:495-498.

Schwanke C. \& Kellner A.W.A. 1999. Presença de perfurações de insetos (Coleoptera?) em ossos isolados de sinapsídeos da Formação Santa Maria, Bacia do Paraná, Triássico do Rio Grande do Sul. In: Congr. Bras. Paleont., 16, Crato, Boletim de Resumos, vol. 1, p.100.

Silva R.C., Ferigolo J., Carvalho I.S., Fernandes A.C.S. 2005a. A new vertebrate ichnocoenosis from the Triassic of Brazil. In: Gondwana 12, Mendoza, Abstracts, vol. 1, p.115.

Silva R.C., Ferigolo J., Ribeiro A.M., Carvalho I.S., Fernandes A.C.S. 2005b. Ocorrência de pegadas fósseis no Grupo Rosário do Sul, Triássico do Estado do Rio Grande do Sul. Paleontologia em Destaque, 20:38.

Silva R.C., Ferigolo J., Carvalho I.S., Fernandes A.C.S. 2006. Pegadas fósseis de Cynodontia (Therapsida) e Theropoda (Dinosauria) do Triássico da Bacia do Paraná. Revista Ciência e Natura volume especial, agosto, p. 38.

Silva R.C., Ferigolo J., Carvalho I.S., Fernandes, A.C.S. 2007a. Morfologia funcional das pegadas de esfenodontídeos do Triássico Superior (Formação Santa Maria) do Sul do Brasil. Paleontologia em Destaque, 22:33.

Silva R.C., Carvalho I.S., Fernandes A.C.S., Ferigolo, J. 2007b. Preservação e contexto paleoambiental das pegadas de tetrápodes da Formação Santa Maria (Triássico Superior) do Sul do Brasil. In: Congr. Bras. Paleont., 20, Búzios, Paleontologia: Cenários da Vida. Editora Interciência, Rio de Janeiro, p.525-532.

Silva, R.C., Ferigolo, F., Carvalho, I.S., Fernandes, A.C.S. 2008. Lacertoid footprints from the Upper Triassic (Santa Maria Formation) of Southern Brazil. Palaeogeography, Palaeoclimatology, Palaeoecology, 262:140-156.

Smith R.M.H. 1993. Sedimentology and Ichnology of Foodplain Paleosurfaces in the Beaufort Group (Late Permian), Karoo Sequence, South Africa. Palaios, 8:339357.

Souto P.R.F. 2001. Tetrapods Coprolites from the Middle Triassic of Southern Brazil. Gaia, 16:51-57.

Swanson B.A. \& Carlson K.J. 2002. Walk, wade or swim? Vertebrate traces on an Early Permian Lakeshore. Palaios, 17:123-133.

Zerfass H., Lavina E.L., Schultz C.L., Garcia A.G.V., Faccini U.F., Chemale Jr. F. 2003. Sequence stratigraphy of continental Triassic strata of southernmost Brazil: a contribution to Southwestern Gondwana palaeogeography and palaeoclimate. Sedimentary Geology, 161:85-105.

Manuscrito ID 9513

Submetido em 08 de outubro de 2007 Aceito em 15 de junho de 2008 Sistema eletrônico de submissão 